\title{
INOVAÇÃO ORGANIZACIONAL DA INDÚSTRIA DE PETRÓLEO, GÁS NATURAL E BIOCOMBUSTÍVEIS - A TERCEIRIZAÇÃO E A GOVERNANÇA CORPORATIVA
}

Classificação JEL: L71 Mining, Extraction, and Refining: Hydrocarbon Fuels.

Jacks Williams Peixoto Bezerra - jacksbezerra@gmail.com

Universidade Federal do Rio de Janeiro - Instituto de Psicologia (Mestrando)

\section{Resumo}

Ao Setor de Petróleo e Gás do Brasil destina-se mais de $\mathrm{R} \$ 50$ bilhões por ano em investimentos. A cadeia de valor do petróleo representa 12\% do Produto Interno Bruto. O atual cenário internacional de preço reduzido do barril do petróleo potencializou a volatilidade e riscos da Indústria. A Inovação é fundamental na estratégia empresarial de competitividade ao permitir ampliar mercados e reduzir custos. A inserção de terceirização, contexto das relações externas da empresa, e de governança corporativa, cenário de organização do trabalho, é inovação organizacional. Na Conclusão, dos terceirizados da Petrobras, há o destaque de ser necessário saber, inclusive, em quais segmentos, áreas, unidades e setores estão sediados e em quais percentuais, bem como pesquisar quais impactos positivos ou negativos apresentam à Indústria, além de se mapear como dimensões de busca, seleção, implementação e captura do valor da inovação são agenciadas. Acerca do novo modelo de governança, Petrobras 2016, que ampliou mecanismos de controle e conformidade, redistribuiu atividades e revisou modelo decisório, afirma-se ser esta governança crucial por conta da grave crise institucional e por causa do comprometimento da Empresa em seguir regras de instituições nacionais e internacionais quanto à transparência e prestação de contas.

Palavras chaves: inovação; inovação organizacional; organização do trabalho; petróleo e gás natural; terceirização.

\begin{abstract}
The Oil \& Gas Brazil meant more than R \$ 50 billion a year in investments. The oil value chain represents $12 \%$ of gross domestic product. The current low price international scenario of a barrel of oil enhanced the volatility and risks Industry. Innovation is key in the business strategy of competitiveness by allowing expand markets and reduce costs. The insertion of outsourcing, external relations of the company, and corporate governance, work organization scenario is organizational innovation. In conclusion, the Petrobras outsourced, there is a prominent need to know, including, in which segments, areas, units and sectors are based and which percentage and research which positive or negative impacts have the industry, in addition to mapping as search dimensions, selection, implementation and capture the value of innovation are brokered. About the new governance model, Petrobras in 2016, which expanded control mechanisms and compliance, redistributed activities and revised decision model, it is stated that this crucial governance because of the serious institutional crisis and because of the company's commitment to follow rules of institutions national and international as transparency and accountability.
\end{abstract}

Key words: innovation; organizational innovation; organization of work; oil and natural gas; outsourcing. 


\section{Introdução}

ALMEIDA (2016), ao problematizar a questão da competitividade do Setor de Petróleo e Gás, no Brasil, pontua que dentre os desafios e estratégias de redução de custos na Exploração e Produção Offshore há a questão das soluções tecnológicas específicas para a complexidade de cada projeto, da tendência de se privilegiar soluções de maior conteúdo tecnológico, mas não necessariamente mais rentáveis e do elevado grau de divisão do trabalho e de terceirização - inclusive pela elevada quantidade de empresas envolvidas nas Operações. Estes Desafios tornam-se, então, ainda mais prementes na realidade do atual mercado internacional do petróleo, no cenário de queda acentuada dos preços do petróleo e, de igual modo, por estratégias já assumidas de grandes players empresariais e de governo deste Mercado - como a questão dos não convencionais nos Estados Unidos e da exploração de areia betuminosa no Canadá.

Neste contexto, destaca-se que a Indústria de Exploração e Produção (E\&P) de Petróleo e Gás, no Brasil, responde a um ambiente de investimento cujos valores ultrapassam R $\$ 77$ bilhões/ano. Em vista disto, a cadeia de valor do petróleo demarca, aproximadamente, $12 \%$ do Produto Interno Bruto. Por sua vez, com relação ao Negócio há a questão de que a descontinuidade de atividades exploratórias tende a resultar na desmobilização de equipes de alto nível técnico, em especial de empresas de menor porte ou para subsidiárias de companhias internacionais com pequenas carteiras de projetos em Exploração e Produção. Por decorrência, a mobilização de novos profissionais no cenário de retomada de atividades levará bem mais tempo e implicará em elevados custos às companhias. Por isto há a urgência de que Leilões, no escopo de novos blocos exploratórios, por exemplo, sejam estimulados para que o risco de interrupção em investimentos - por toda a Cadeia - seja reduzido, mantendo-se com isto a sustentabilidade do Negócio. Neste processo há a previsão de que, até o ano de 2020, aproximadamente R\$ 950 bilhões sejam encaminhados, no País, em investimentos e gastos diretos - cadeia de bens e serviços em óleo e gás. Deste modo, ressalta-se o fato de que na última década houve relevante aumento no patamar de investimentos em petróleo e gás, o que provocou o aumento de demanda da Indústria em cinco vezes, sem que houvesse, todavia, o acompanhamento, mesmo com o crescimento da oferta local, das novas demandas por produtos, serviços e mão de obra. (IBP, [201-], p. 17-19)

Nesta dinâmica, o Brasil, no que diz respeito a indicadores de inovação, desenvolve a Pesquisa de Inovação - PINTEC, que é uma pesquisa-satélite de corte transversal do Sistema de Estatísticas Econômicas e que dinamiza Indicadores abrangentes e com comparabilidade internacional tanto em termos conceituais quanto metodológicos. Esta Pesquisa é realizada pelo Instituto Brasileiro de Geografia e Estatística (IBGE) e conta com o apoio da Financiadora de Estudos e Projetos (FINEP) e do Ministério da Ciência, Tecnologia e Inovação (MCTI).

Nesse cenário de Pesquisas PINTEC, este Artigo agencia as Pesquisas de Inovação Tecnológica 2008 e Pesquisa de Inovação 2011. Isto se deve pela questão de que a partir da Pintec 2008 a Inovação passou a ser analisada mediante um mais amplo conceito, ou seja, não somente inovação tecnológica de produto e processo, e que incorporou, deste modo, as inovações não tecnológicas. Em vista disto, há o destaque para se considerar que a implementação de novidades organizacionais pode melhorar o uso do conhecimento, bem como a eficiência dos fluxos de trabalho e, por fim, a própria qualidade dos bens e serviços de empresas. Vale a observação de que tem início pela PINTEC 2008 a pesquisa sobre inovações de marketing. (IBGE, 2010, p. 57) 
Deste modo, há a comunicação de que a PINTEC reconhece que a Inovação Organizacional - que não inclui fusões e aquisições, mesmo sendo a primeira vez,

... compreende a implementação de novas técnicas de gestão ou de significativas mudanças na organização do trabalho e nas relações externas da empresa, com vistas a melhorar o uso do conhecimento, a eficiência dos fluxos de trabalho ou a qualidade dos bens ou serviços. Deve ser resultado de decisões estratégicas tomadas pela direção e constituir novidade organizativa para a empresa. (IBGE, 2010, p. 156)

Em vista disto, o que a PINTEC busca desvendar de forma objetiva é se houve:

- 188 Novas técnicas de gestão para melhorar rotinas e práticas de trabalho, assim como o uso e a troca de informações, de conhecimento e habilidades dentro da empresa. Por exemplo: re-engenharia dos processos de negócio, gestão do conhecimento, controle da qualidade total, sistemas de formação/treinamento, SIG (sistemas de informações gerenciais), ERP (planejamento dos recursos do negócio) etc.

- 189 Novas técnicas de gestão ambiental para tratamento de efluentes, redução de resíduos, de $\mathrm{CO}_{2}$ etc.

- 190 Novos métodos de organização do trabalho para melhor distribuir responsabilidades e poder de decisão, como por exemplo o estabelecimento do trabalho em equipe, a descentralização ou integração de departamentos etc.

- 190.1 Mudanças significativas nas relações com outras empresas ou instituições públicas e sem fins lucrativos, tais como o estabelecimento pela primeira vez de alianças, parcerias, terceirização ou sub-contratação de atividades. (IBGE, 2010, p. 156)

Em vista disto, este Artigo norteado por conceitos das PINTEC/IBGE 2008 e 2011, incluindo referenciais do Manual de Oslo (OCDE, 1997), tematiza o cenário da Inovação Organizacional - Relações Externas e Organização do Trabalho - nas Áreas de fabricação de coque, de produtos derivados do petróleo e de biocombustíveis; de fabricação de coque e biocombustíveis (álcool e outros); de refino de petróleo. Isto se deve, inclusive, pelo fato da intensa competitividade e relevância que o Setor tem para a Economia do País, bem como pela significância que a Terceirização e a Governança Corporativa têm para a sustentabilidade empresarial e social.

\section{Objetivo}


O objetivo do Artigo é o de problematizar a interface e a relevância estratégica que há entre inovação organizacional (mudanças nas relações com outras empresas/terceirização e novos métodos de organização do trabalho/governança corporativa) e a sustentabilidade empresarial da Indústria do Petróleo, Gás Natural e Biocombustíveis do Brasil. Microcenário da cadeia produtiva do Setor, o da Petrobras, permite a pesquisa investigativa. Informações (conceitos e dados) do Manual de Oslo e da Série PINTEC 2008 e 2011 - no cenário da fabricação de coque, de produtos derivados do petróleo e de biocombustíveis; da fabricação de coque e biocombustíveis (álcool e outros); do refino de petróleo - oferecem suporte analítico à reflexão crítica.

\section{Metodologia}

O Método de Procedimento adotado para a coleta de dados e informações e para a Análise vincula-se ao Método Monográfico (Prodanov e Freitas, 2013, p. 39), o qual tem como princípio norteador que o estudo de um caso pode ser representativo de outros ou de todos os casos semelhantes. Deste modo, o estudo de caso diz respeito a indivíduos, a grupos, a comunidades e a instituições. O Estudo de Caso desta Pesquisa refere-se à Inovação Organizacional quanto à Terceirização e à Governança Corporativa da Petrobras - cujos dados e informações são de domínio público quando disponibilizados em relatórios institucionais e em demais plataformas eletrônicas abertas da Empresa. Em vista disto, neste escopo promoveu-se levantamentos bibliográficos, documentais e estatísticos, além do Estudo de Caso selecionado. A Conclusão apresenta proposta de desdobramento de pesquisa, além de encerrar a presente análise crítica.

O Artigo está dividido em onze Seções - incluindo a Introdução e a Conclusão. A segunda Seção apresenta o Objetivo e a terceira a Metodologia. A quarta destaca aspectos de inovação e competitividade e se detém no Manual de Oslo. A quinta se pauta na PINTEC Pesquisa de Inovação Tecnológica 2008 e a sexta na PINTEC Pesquisa de Inovação 2011. A sétima integra Reflexão acerca das 2 Pesquisas PINTEC. A oitava agencia o cenário político e econômico da Indústria internacional de petróleo, gás natural e biocombustíveis e o Brasil neste contexto. A nona pontua a gestão organizacional, a organização do trabalho e a terceirização. A décima apresenta informação sobre a Terceirização e a Organização do Trabalho da Petrobras.

Em vista disto, para a primeira e a oitava Seções do Artigo, subsídios acerca da Indústria de petróleo e gás natural foram levantados na página eletrônica do Grupo de Economia da Energia da Universidade Federal do Rio de Janeiro - no seu Boletim Infopetro. Este cenário se completa por informações constantes do portal eletrônico do Instituto Brasileiro de Petróleo, Gás e Biocombustíveis - IBP. Para a quarta Seção, a tradução do Manual de Oslo foi acessada no endereço eletrônico da Financiadora de Estudos e Projetos - FINEP. Para a primeira, quinta e sexta Seções, informações acerca das Pesquisas PINTEC Inovação Tecnológica 2008 e Pesquisa de Inovação 2011 foram coletas do sítio eletrônico do Instituto Brasileiro de Geografia e Estatística - IBGE. Para a nona Seção, informações sobre terceirização foram buscadas no website da Confederação Nacional da Indústria - CNI. Para a décima Seção, o cenário Petrobras foi identificado mediante a sua própria divulgação corporativa: páginas da internet. Completa este arcabouço teórico e conceitual a pesquisa em fontes bibliográficas.

\section{A Inovação, a Competitividade e o Manual de OSLO}


SICSÚ (2015, p. 2-3) cita a importância de se garantir maior apropriação dos êxitos de avanços científicos e tecnológicos que permitam a Inovação. O foco é a garantia da expansão de investimentos para melhores condições de desenvolvimento. Ao citar Schumpeter (1982), ressalta o empresário inovador, que apresenta produtos, em especial inovações tecnológicas, com vistas a lucros extraordinários. Este agente, por novas combinações, inova quanto a bens, métodos de produção e transportes. Cria mercados, fontes de matéria-prima e formas de organizar a produção também novos.

Em vista disto, o empresário inovador, ao correr riscos, promove a destruição criativa - Schumpeter (1984) citado por Sicsú (2015, p. 5). Assim, para que o sistema evolua se faz necessário o sucateamento de processos de produção ao longo do tempo para que sejam abertos espaços para hábitos novos de consumo. Esta dinâmica representa o impulso fundamental que inicia e mantém a engrenagem capitalista - a busca pelo novo. Variáveis tais como a cultura inovadora, o perfil inovador na classe empresarial e os mecanismos de financiamento e crédito, dentre outros elementos, são fundamentais para a inserção e constância do processo inovador, ou seja, para a Inovação.

Neste contexto, o processo de inovação na organização, conforme Tidd e Bessant (2015, p. 55), contempla quatro dimensões: a busca mediante a qual se analisa o cenário interno e externo de ameaças e oportunidades de mudança. A seleção a partir da qual se decide, pelo viés de estratégia empresarial, qual dos sinais identificados, na análise dos cenários, será trabalhado. A implementação, que traduz o potencial da ideia inicial assumir algo novo: a ser lançado em mercado interno ou externo (mas demanda conhecimentos) pela realização de projetos sob condições de imprevisibilidade e por capacidade de resolução de problemas. A captura de valor por meio da inovação, que agencia as dimensões de adoção sustentável e de difusão, bem como de aprendizado associado à progressão de longo ciclo e voltado ao aperfeiçoamento contínuo.

Deste modo, sendo Inovação a principal opção estratégica para erguer a competitividade de empresas, Pelegrin e Antunes Júnior (2015, p. 17) destacam que é mediante a inovação que a firma se insere em novos mercados, ou seja, introdução de novo produto ou serviço, ampliação geográfica de produtos existentes e combinação de novos serviços e/ou produtos em espaços geográficos novos. Ressalta (Ibid, p. 21) o conceito de ganhos relacionais, que faz referência àqueles resultados que a organização não consegue alcançar de forma individual, ou seja, somente conquista os ganhos por meio de relacionamentos qualificados com demais agentes - acesso a recursos externos.

Assim, relevante é destacar a questão da competitividade. O Manual de Oslo (OCDE, 1997, p. 43) assinala que inovações visam o desempenho da firma e que mudanças são agenciadas por pressupostos de que a Inovação: está associada a incertezas quanto a resultados; envolve investimento de ativos fixos e/ou intangíveis; é o substrato de transbordamentos para o Mercado; requer a utilização de conhecimento novo ou de novo uso ou combinação do conhecimento que existe; visa o ganho de vantagem competitiva ou da manutenção da competitividade, digo, desempenho de mercado. Isto significa mudança da curva de demanda de seus produtos ou serviços (aumento ou expansão de mercados e consumidores) ou de sua curva de custos (redução). Inclui o aprimoramento de sua capacidade de inovação (maior capacidade de desenvolver produtos, processos e/ou conhecimentos novos).

Deste modo, o Manual de OSLO é desenvolvido pela Organização para a Cooperação e Desenvolvimento Econômico - OCDE e pela Autoridade Estatística da 
União Europeia - Eurostat. Constitui parte de família de manuais circunscrita à mensuração e interpretação de dados de ciência, tecnologia e inovação. O Material engloba manuais, diretrizes e guias sobre: pesquisa e desenvolvimento (Manual Frascati); sociedade da informação; indicadores de globalização; patentes; estatísticas de biotecnologia; recursos humanos em ciência e tecnologia (Manual Canberra). (OCDE, 1997, p. 12)

Em vista disto, políticas de suporte apropriado a inovações, para que sejam de fato desenvolvidas, necessitam de melhor entendimento acerca de aspectos que são críticos para o processo inovador. Destaca-se atividades de inovação não inseridas na Pesquisa e Desenvolvimento, bem como interações entre atores, além de fluxos relevantes de conhecimento - incluindo acesso a informações significativas. (OCDE, 1997, p. 15)

Deste modo, o Manual de Oslo (OCDE, 1997, p. 25), inovação no âmbito da firma, esclarece que a Inovação inclui Atividades que não se inserem em Pesquisa e Desenvolvimento: últimas fases do desenvolvimento para pré-produção, produção e distribuição (inclui atividades de desenvolvimento com menor grau de novidade); desenvolvimento e implementação para inovações como métodos novos tanto de marketing quanto organizacionais, que não são inovações nem de produto e nem de processo; de suporte como treinamento e preparação para o mercado. Atividades de inovação também podem incluir a aquisição de conhecimentos externos, bem como bens de capital que não são parte da P\&D. Há, então, o seguinte conceito:

Uma inovação é a implementação de um produto (bem ou serviço) novo ou significativamente melhorado, ou um processo, ou um novo método de marketing, ou um novo método organizacional nas práticas de negócios, na organização do local de trabalho ou nas relações externas. (OCDE, 1997, p. 55)

Neste sentido, a inovação organizacional é conceituada como "a implementação de um novo método organizacional nas práticas de negócios da empresa, na organização do seu local de trabalho ou em suas relações externas”. Esta Inovação pode visar o aperfeiçoamento de uma empresa a partir da redução de custos administrativos ou de transação. Estimula a satisfação no local de trabalho - potencial impacto na produtividade -, o ganho no acesso a ativos não transacionais (tal como conhecimento externo não codificado) ou a redução de custos de suprimentos. (OCDE, 1997, p. 61-62)

Em vista disto, inovações na organização do local de trabalho

... envolvem a implementação de novos métodos para distribuir responsabilidades e poder de decisão entre os empregados na divisão de trabalho existente no interior das atividades da empresa (e unidades organizacionais) e entre essas atividades. Participam também novos conceitos para a estruturação de atividades, tais como a integração de diferentes atividades de negócio. (OCDE, 1997, p. 62)

Por sua vez, novos métodos organizacionais nas relações externas de uma empresa

... compreendem a implementação de novos meios para organizar as relações com outras firmas ou instituições públicas, tais como o estabelecimento de novos tipos de colaborações com organizações de pesquisa ou consumidores, novos métodos de integração com fornecedores e o uso de outsourcing ou a introdução da subcontratação das atividades de negócios na produção, no aprovisionamento, na distribuição, no recrutamento e em serviços auxiliares. (OCDE, 1997, p. 63)

\section{PINTEC - Pesquisa de Inovação Tecnológica 2008}




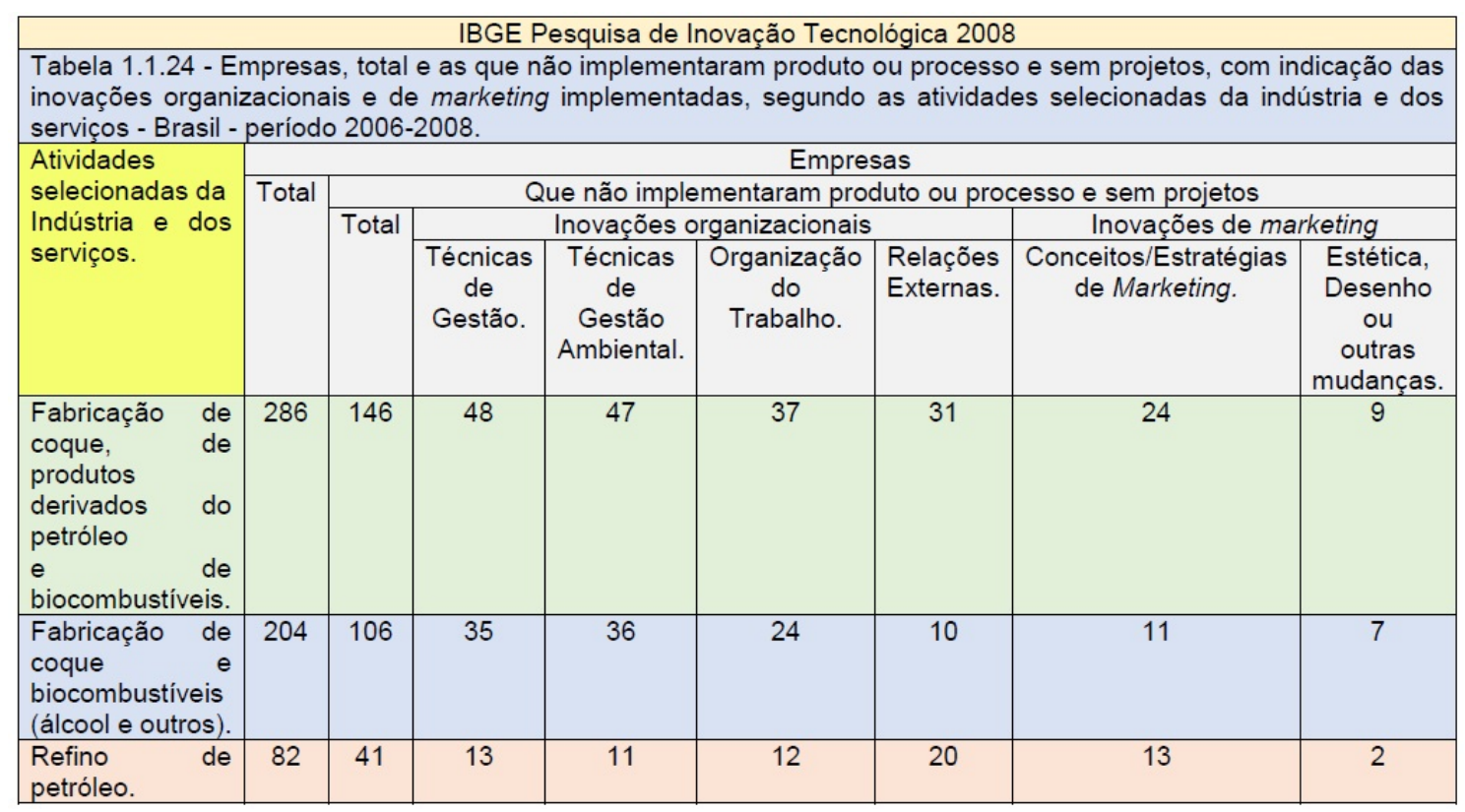

Tabela 1 - elaborada pelo Autor / Fonte: Pesquisa de Inovação Tecnológica 2008. p. 130-131.

Tabela 1: nas Inovações Organizacionais, período 2006-2008, de 286 empresas de fabricação de coque, produtos derivados do petróleo e de combustíveis, 51.45\% (146) não implementaram produto ou processo e apresentaram-se sem projetos. Inovações na Divisão do Trabalho foram feitas por até 37 das empresas e de Terceirização por até 31. Nos estabelecimentos de fabricação de coque e biocombustíveis (álcool e outros) de 204 empresas, 106 (51.96\%) não implementaram produto ou processo e apresentaram-se sem projetos. Inovações de Divisão do Trabalho foram feitas por até 24 das empresas e de Terceirização por até 10 . No refino de petróleo, de 82 empresas, 41 (50\%) não implementaram produto ou processo e apresentaram-se sem projetos. Inovações de Divisão do Trabalho foram feitas por até 12 das empresas e de Terceirização por até 20.

\begin{tabular}{|c|c|c|c|c|c|c|c|c|}
\hline & & & IBGE P & esquisa de I & novação Tecnc & lógica 2008 & & \\
\hline $\begin{array}{l}\text { Tabela 1.1.25 - El } \\
\text { de marketing impl } \\
2008 .\end{array}$ & $\begin{array}{l}\text { npresa } \\
\text { ementa }\end{array}$ & $\begin{array}{l}\text { s, total } \\
\text { das, } s \in\end{array}$ & $\begin{array}{l}\text { e as que in } \\
\text { gundo as }\end{array}$ & $\begin{array}{l}\text { plementarar } \\
\text { tividades se }\end{array}$ & $\begin{array}{l}\text { n inovações, c } \\
\text { lecionadas da }\end{array}$ & $\begin{array}{l}\text { m indicaçã } \\
\text { ndústria e }\end{array}$ & $\begin{array}{l}\text { das inovações organi } \\
\text { os serviços - Brasil - pe }\end{array}$ & $\begin{array}{l}\text { acionais e } \\
\text { íodo } 2006 \text { - }\end{array}$ \\
\hline Atividades & & & & & Empre & as & & \\
\hline selecionadas da & Total & & & & Que implemer & taram inov & ções & \\
\hline Indústria e dos & & Total & & Inovações o & rganizacionais & & Inovações de ma & keting \\
\hline serviços. & & & $\begin{array}{l}\text { Técnicas } \\
\text { de } \\
\text { Gestão. }\end{array}$ & $\begin{array}{l}\text { Técnicas } \\
\text { de } \\
\text { Gestão } \\
\text { Ambiental. }\end{array}$ & $\begin{array}{c}\text { Organização } \\
\text { do } \\
\text { Trabalho. }\end{array}$ & $\begin{array}{l}\text { Relações } \\
\text { Externas. }\end{array}$ & $\begin{array}{c}\text { Conceitos/Estratégias } \\
\text { de Marketing. }\end{array}$ & $\begin{array}{c}\text { Estética, } \\
\text { Desenho } \\
\text { ou } \\
\text { outras } \\
\text { mudanças. }\end{array}$ \\
\hline $\begin{array}{ll}\text { Fabricação } & \text { de } \\
\text { coque, } & \text { de } \\
\text { produtos } & \\
\text { derivados } & \text { do } \\
\text { petróleo } & \\
\text { e } & \text { de } \\
\text { biocombustiveis. }\end{array}$ & 286 & 131 & 72 & 73 & 69 & 16 & 41 & 44 \\
\hline $\begin{array}{l}\text { Fabricação de } \\
\text { coque } \\
\text { biocombustíveis } \\
\text { (álcool e outros). }\end{array}$ & 204 & 94 & 51 & 57 & 47 & 10 & 23 & 30 \\
\hline $\begin{array}{l}\text { Refino de } \\
\text { petróleo. }\end{array}$ & 82 & 37 & 21 & 16 & 22 & 6 & 19 & 13 \\
\hline
\end{tabular}

Tabela 2 - elaborada pelo Autor / Fonte: Pesquisa de Inovação Tecnológica 2008. p. 132-133.

A Tabela 2 destaca, nas Inovações Organizacionais, período 2006-2008, que de 286 empresas de fabricação de coque, de produtos derivados do petróleo e de combustíveis, 
45.80\% (131) implementaram inovações. Inovações de Divisão do Trabalho foram feitas por até 69 das empresas e de Terceirização por até 16. Relacionado à fabricação de coque e biocombustíveis (álcool e outros) há o seguinte: de 204 empresas, 94 (46.08\%) implementaram inovações. No que concerne à Divisão do Trabalho, inovações foram feitas por até 47 das empresas. Já inovações relativas à Terceirização ocorreram em até 10 das mesmas empresas. No contexto do refino de petróleo, de 82 empresas, inovações foram realizadas em 37 (45.12\%). Assim, inovações de Divisão do Trabalho foram feitas por até 22 das empresas e de Terceirização podem ter sido feitas por até 6 das empresas.

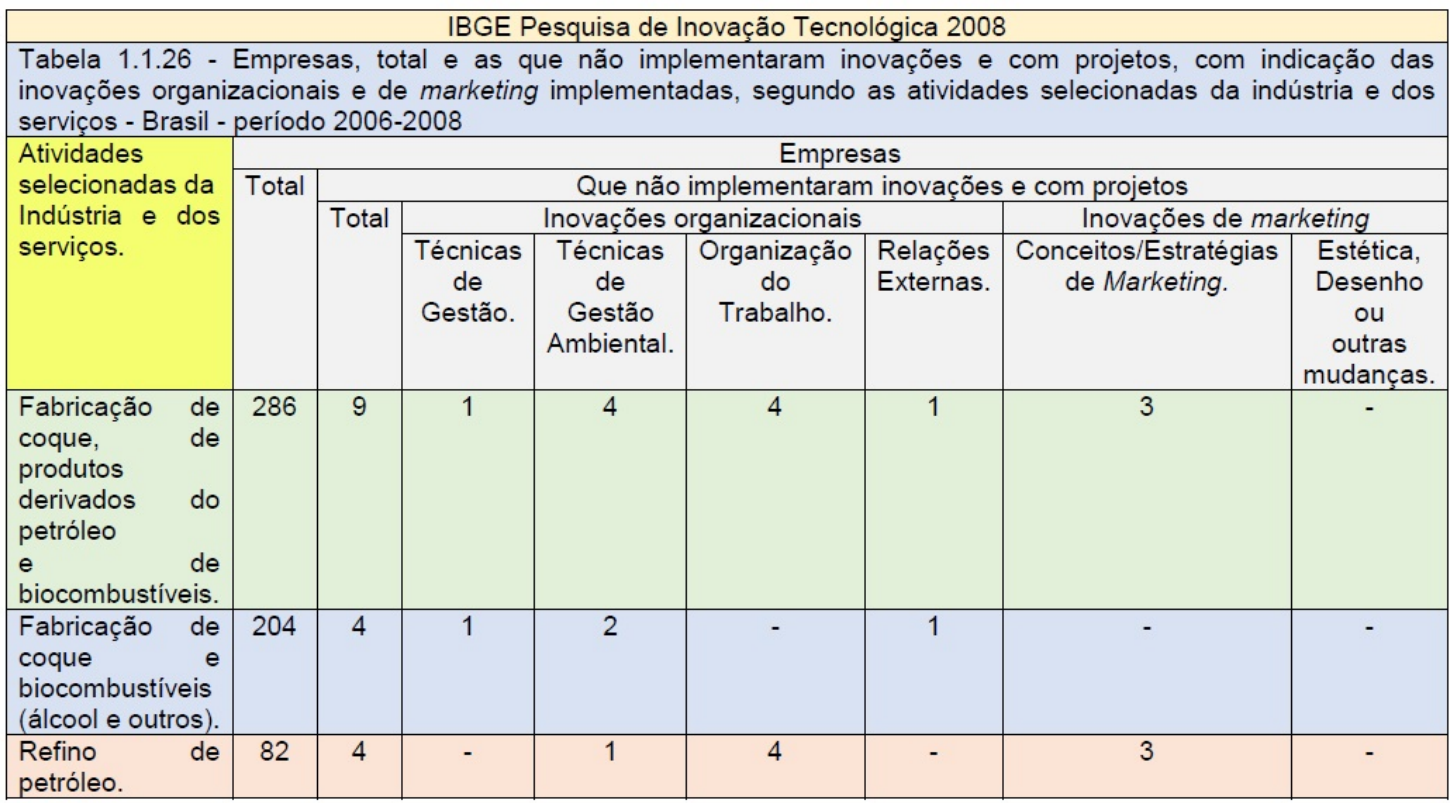

Tabela 3 - elaborada pelo Autor / Fonte: Pesquisa de Inovação Tecnológica 2008. p. 134-135.

A Tabela 3 indica, nas Inovações Organizacionais, período 2006-2008, que de 286 empresas de fabricação de coque, de produtos derivados do petróleo e de combustíveis, 3.15\% (9) não implementaram inovações, mas apresentaram-se com projetos. Por sua vez, Inovações de Divisão do Trabalho foram feitas por até 4 das empresas e de Terceirização foi feita por até 1 empresa.

No que diz respeito à fabricação de coque e biocombustíveis (álcool e outros) há o seguinte: de 204 empresas, 4 (1.96\%) não implementaram inovações, mas apresentaram-se com projetos. No que concerne à Divisão do Trabalho, não houve inovação. Inovação relativa à Terceirização ocorreu em até 1 das empresas. No cenário do refino de petróleo, de 82 empresas, 4.88\% (4) não implementaram inovações, mas apresentaram-se com projetos. Inovações de Divisão do Trabalho foram feitas por até 4 das empresas e Terceirização não foi implementada por estas empresas. 


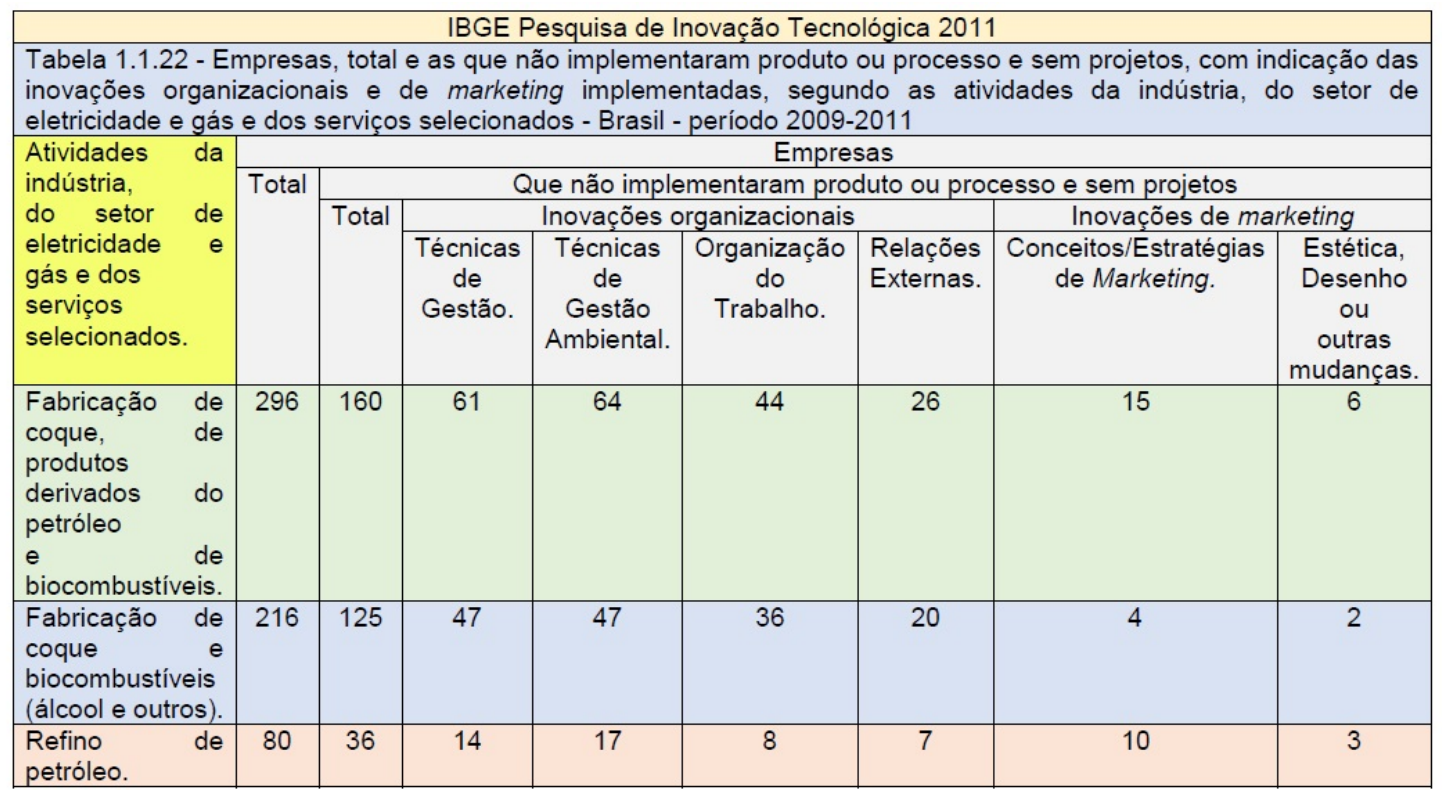

Tabela 4 - elaborada pelo Autor / Fonte: Pesquisa de Inovação 2011. p. 181-183.

Tabela 4: em Inovações Organizacionais, período 2009-2011, de 296 empresas de fabricação de coque, de produtos derivados do petróleo e de combustíveis, $54.05 \%$ (160) não implementaram produto ou processo e apresentaram-se sem projetos. Inovações de Divisão do Trabalho foram feitas por até 44 das empresas e de Terceirização por até 26. Na fabricação de coque e biocombustíveis (álcool e outros), de 216 empresas, 125 (57.87\%) não implementaram produto ou processo e apresentaramse sem projetos. Na Divisão do Trabalho, inovação foi feita em até 36 empresas e em Terceirização por até 20. No refino de petróleo, de 80 empresas, 45\% (36) não implementaram produto ou processo e apresentaram-se sem projetos. Inovações de Divisão do Trabalho foram feitas por até 8 das empresas e de Terceirização em até 7.

\begin{tabular}{|c|c|c|c|c|c|c|c|c|}
\hline \multicolumn{9}{|c|}{ IBGE Pesquisa de Inovação Tecnológica 2011} \\
\hline \multicolumn{9}{|c|}{$\begin{array}{l}\text { Tabela 1.1.23 - Empresas, total e as que implementaram inovações, com indicação das inovações organizacionais e } \\
\text { de marketing implementadas, segundo as atividades da indústria, do setor de eletricidade e gás e dos serviços } \\
\text { selecionados - Brasil - período 2009-2011 }\end{array}$} \\
\hline \multirow{4}{*}{$\begin{array}{lr}\text { Atividades } & \text { da } \\
\text { indústria, } & \\
\text { do setor de } \\
\text { eletricidade } \\
\text { gás e dos } \\
\text { serviços } \\
\text { selecionados. }\end{array}$} & \multirow{4}{*}{ Total } & \multicolumn{7}{|c|}{ Empresas } \\
\hline & & \multicolumn{7}{|c|}{ Que implementaram inovações } \\
\hline & & \multirow[t]{2}{*}{ Total } & \multicolumn{4}{|c|}{ Inovações organizacionais } & \multicolumn{2}{|c|}{ Inovações de marketing } \\
\hline & & & $\begin{array}{l}\text { Técnicas } \\
\text { de } \\
\text { Gestão. }\end{array}$ & $\begin{array}{c}\text { Técnicas } \\
\text { de } \\
\text { Gestão } \\
\text { Ambiental. }\end{array}$ & $\begin{array}{l}\text { Organização } \\
\text { do } \\
\text { Trabalho. }\end{array}$ & $\begin{array}{l}\text { Relações } \\
\text { Externas. }\end{array}$ & $\begin{array}{c}\text { Conceitos/Estratégias } \\
\text { de Marketing. }\end{array}$ & $\begin{array}{l}\text { Estética, } \\
\text { Desenho } \\
\text { ou } \\
\text { outras } \\
\text { mudanças. }\end{array}$ \\
\hline $\begin{array}{ll}\text { Fabricação } & \text { de } \\
\text { coque, } & \text { de } \\
\text { produtos } & \\
\text { derivados } & \text { do } \\
\text { petróleo } & \\
\text { e } & \text { de } \\
\text { biocombustíveis. }\end{array}$ & 296 & 113 & 92 & 76 & 63 & 39 & 19 & 24 \\
\hline $\begin{array}{l}\text { Fabricação de } \\
\text { coque } \\
\text { biocombustíveis } \\
\text { (álcool e outros). }\end{array}$ & 216 & 69 & 60 & 52 & 48 & 16 & 4 & 4 \\
\hline $\begin{array}{ll}\text { Refino } & \text { de } \\
\text { petróleo. } & \\
\end{array}$ & 80 & 43 & 31 & 24 & 16 & 23 & 14 & 20 \\
\hline
\end{tabular}

Tabela 5 - elaborada pelo Autor / Fonte: Pesquisa de Inovação 2011. p. 185-187.

A Tabela 5 apresenta, em especial Inovações Organizacionais, período 2009-2011, que de 296 empresas de fabricação de coque, de produtos derivados do petróleo e de 
combustíveis, 38.17\% (113) implementaram inovações. Inovações de Divisão do Trabalho foram feitas por até 63 das empresas e em Terceirização em até 39 empresas. Na fabricação de coque e biocombustíveis (álcool e outros): de 216 empresas, 69 (31.94\%) implementaram inovações. Inovações, na Divisão do Trabalho, ocorreram em até 48 empresas e em Terceirização em até 16 empresas. No refino de petróleo, de 80 empresas, $53.75 \%$ (43) implementaram inovações. Inovações de Divisão do Trabalho foram feitas por até 16 das empresas. Terceirização foi agenciada por até 23 empresas.

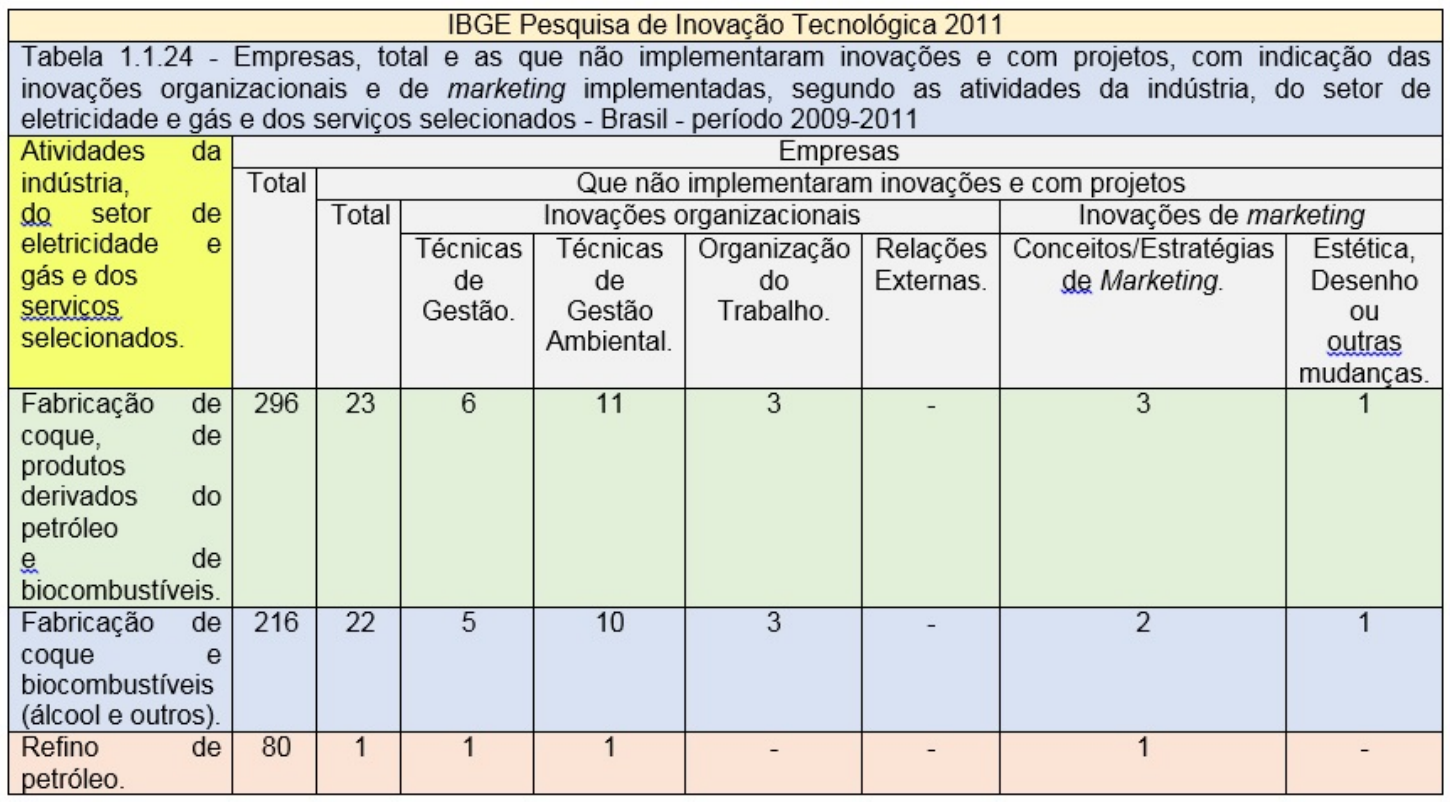

Tabela 6 - elaborada pelo Autor / Fonte: Pesquisa de Inovação 2011. p. 189-191.

A Tabela 6 ressalta, nas Inovações Organizacionais, período 2009-2011, que de 296 empresas de fabricação de coque, de produtos derivados do petróleo e de combustíveis, 7.77\% (23) não implementaram inovações, mas apresentaram-se com projetos. Neste cenário, no que concerne às Inovações de Divisão do Trabalho, estas foram feitas por até 3 das empresas. Inovação em Terceirização não ocorreu. Nas empresas com fabricação de coque e biocombustíveis (álcool e outros), de 216 empresas, 22 (31.94\%) não implementaram inovações, mas apresentaram-se com projetos. Na Divisão do Trabalho, inovação pode ter ocorrido em até 3 empresas. Inovação em Terceirização não foi indicada. No refino de petróleo, de 80 empresas, 1 empresa (1.25\%) não implementou inovação, mas apresentou-se com projetos. Não houve indicação de inovação na Divisão do Trabalho e nem de Terceirização.

Em vista do destacado pelas seis Tabelas apresentadas, PINTEC 2008 e PINTEC 2011, importante é assinalar que a Série PINTEC/IBGE, Pesquisa de corte transversal (IBGE, 2013, p. 12-13), objetiva construir Indicadores setoriais, regionais e nacionais quanto às atividades de inovação em empresas do Setor da Indústria e de Indicadores nacionais de inovação em empresas dos setores de Eletricidade e Gás e de Serviços selecionados - de forma compatível com Recomendações internacionais: metodologia e conceitos. Assim, os Indicadores gerados, além de uso por parte de empresas (análise do mercado) e por associações de classe (análise de desempenho), servem de subsídio para o desenvolvimento e avaliação de Políticas Públicas nacionais e regionais.

PINTEC - Pesquisa de Inovação Tecnológica 2008 e Pesquisa de Inovação 2011 
A PINTEC se articula com demais pesquisas estruturais de subsistemas de estatísticas indústrias e de serviços do País. Deste modo, fica mais claro compreender o porquê de não haver dados mínimos, precisos e pontuais acerca de qual qualidade ou escopo de Inovação Organizacional foi de fato realizada em cada empresa. O Instrumento investigativo, ou seja, o Questionário PINTEC/IBGE aplicado em cada empreendimento industrial ou de serviço questiona, de forma objetiva, quanto às inovações organizacionais, de um modo geral, se houve ou não, ou seja, resposta sim ou não - inovação de novas técnicas de gestão, de novas técnicas de gestão ambiental, de novos métodos de organização do trabalho e de mudanças significativas nas relações com outras empresas e instituições (IBGE, 2013, p. 217).

Em vista disto, será na dinâmica completa de pesquisa, análise e avaliação de inovação organizacional, no ambiente de intrafirma, que a realidade ou precisão acerca da Inovação será de fato apreendida. Vale ressaltar, por sua vez, que o cenário das Inovações Organizacionais, como apresentado pela Série PINTEC/IBGE, para o seu melhor entendimento, também precisa levar em conta e se articular com os demais dados e sínteses que a Série em questão compartilha quanto a outras Variáveis ou Áreas investigadas, tais como: gastos com as atividades inovativas; arranjos cooperativos estabelecidos; obstáculos encontrados às atividades de inovação.

Deste modo, por exemplo, chama a atenção - Tabela 1, o alto percentual de empresas, cerca de 50\% em cada Segmento, que não implementaram produtos ou processos e sem que possuíssem, na ocasião, projetos. A Tabela 2, que também contempla empresas que implementaram inovações, nos assinala o baixo quantitativo de empresas que inovaram em suas Relações Externas, que diz respeito à Terceirização, isto nos três segmentos produtivos (horizontais). A Tabela 3, indicando empresas que não inovaram, mas que tinham projetos de inovação, ressalta baixíssimo quantitativo, inclusive nulo, de inovação nas Áreas de divisão do trabalho e de terceirização.

Nesta dinâmica, a Tabela 4, que inicia o período de 2011, tal como a Tabela 1, apresenta alto percentual de empresas, em torno de $45 \%$ a $55 \%$, que não implementaram produtos ou processos e que não possuíam, na ocasião, projetos. No refino do petróleo, baixo percentual de inovação nas dimensões da divisão do trabalho e da terceirização. A Tabela 5, no contexto de empresas que inovaram, pontua considerável quantitativo de empresas - setor de fabricação de coque, de produtos derivados do petróleo e de biocombustíveis - que inovaram na Área de organização do trabalho, que contempla a divisão do trabalho, bem como alto índice de inovação quanto às relações externas, onde se situa a terceirização - no refino do petróleo. A Tabela 6, que concerne a empresas que não implementaram inovações, mas que tinham projetos, nos informa que quanto a inovações organizacionais não houve indicação de inovações relacionadas à divisão do trabalho e a relações externas.

Por fim, relevante é destacar que o puro quantitativo global de inovação organizacional ou não, em cada um dos três Segmentos produtivos, por si só não retrata a complexidade de cada Negócio, de suas operações cotidianas e de suas realizações quanto à Inovação Organizacional. Somente o diagnóstico particular mais completo e sistêmico, intrafirma, é que será na verdade capaz de indicar o quanto se avançou ou não e com qual qualidade e profundidade em cada inovação ou série de inovações.

A Indústria Internacional de Petróleo, Gás Natural e Biocombustíveis e o Brasil 
O Setor de Energia do Brasil, em especial o pertinente ao Petróleo, Gás e Biocombustíveis, tem tido importantes mudanças e impactos no seu ambiente de negócio, em especial a partir de 2014, por decorrência de fatores internos e externos condição do Mercado Internacional de Petróleo e de geopolítica mundial.

Em vista disto, Almeida (2013, p. 32) destaca o complexo cenário econômico e financeiro do período, como: o controle dos preços de derivados de petróleo que impôs relevantes perdas ao Brasil; a crise financeira da empresa OGX; as consequências negativas quanto à ausência de Rodadas de Licitação nos cinco anos anteriores. Neste contexto, por decorrência inclusive de defasados preços de derivados de petróleo, a Petrobras precisou importar quantidade recorde de combustíveis e de gás natural. Assim, a contenção de preços da gasolina provocou impactos negativos também ao etanol. Por fim, grande quantidade de importação de GNL - gás natural liquefeito - foi realizada para fins de viabilização do despacho térmico. A dificultosa condição da Petrobras, que adotou a Disciplina de Capital, impactou a cadeia de fornecedores por decorrência da Política de Redução de Custos quanto às compras de bens e serviços.

No que diz respeito ao balanço do Setor de Energia do Brasil, no ano de 2014, Almeida e Losekann (2014, p. 33) assinalam que este período teve agenda bastante negativa e que há grande conjunto de problemas, antigos e novos, nos Setores elétrico e de óleo e gás do País. Em vista disto, sérios problemas de Governança Institucional da Petrobras a colocaram em xeque de credibilidade perante parceiros, fornecedores, credores e investidores - inclusive por responder por dívida de US\$ 112 bilhões (17\% superior aos valores de 2013). Tal situação ofuscou o que de positivo houve ao longo do ano como o aumento de $10 \%$ na produção de petróleo no período de janeiro a outubro. De igual importância foi o início da operação do primeiro módulo da Refinaria de Pernambuco (Rnest). Mas a questão dos derivados do petróleo só agravou a situação da Empresa, uma vez que a tentativa de se evitar o aumento da inflação, mediante decisão de segurar os preços dos derivados, fez com que as perdas com importações de derivados, em agosto de 2014, atingissem os R\$ 3.7 bilhões.

Neste processo, significativo é destacar que preços mais baixos do petróleo, no mercado internacional, indicam queda de receitas nas exportações - que também impacta a Política de reajuste de preços de derivados no mercado interno. Em vista disto, tendo a Petrobras a necessidade de investir U\$ 50 bilhões ao ano, no período 2015-2018, a realidade de queda acentuada do preço do petróleo não é algo para se comemorar - ao contrário. Neste ano de 2014, a Ação Preferencial da Empresa caiu de R \$20 (em janeiro) para R\$12 - em dezembro. Por sua vez, a Agência de Risco Moody’s rebaixou o rating global, em moeda estrangeira e local, da Petrobras de Baa1 para Baa2 - mantendo a perspectiva negativa. (ALMEIDA \& LOSEKANN, 2014, p. 34)

Nesta dinâmica, Almeida e Losekann (2014, p. 34) ressaltam que a crise da Petrobras afetou todo o Segmento de óleo e gás no País. Negociações mais duras com fornecedores e a decisão de priorizar Segmentos de maior impacto no seu fluxo de caixa influenciaram a redução da atividade de Exploração. Assim, o número de sondas em operação caiu em 2014, tendo a mesma situação quanto a números de poços perfurados. Em um cenário no qual a Petrobras prioriza o Pré-sal, não foi surpreendente que a maior redução exploratória ocorresse no segmento onshore, além de maior dificuldade vivenciada por empresas independentes quanto a investimentos. Para agravar o ambiente de negócio, tanto o Estado do Paraná quanto o da Bahia suspenderam o processo de fraturamento hidráulico - Ação do Ministério Público Federal e Ação de 
Liminar - até que o Conselho Nacional do Meio Ambiente regulamentasse esta Atividade mediante estudos técnicos que indicassem a viabilidade do fraturamento.

Neste cenário da Indústria do Petróleo no Brasil, Colomer e Rodrigues (2015, p. 49) destacam que o Setor de Exploração e Produção (E\&P), no ano de 2013, foi responsável por R\$ 60 bilhões de investimento, por $5.7 \%$ da formação bruta de capital e por 60 mil empregos. Até aquele momento, os investimentos na exploração, na produção e no segmento Downstream tiveram positiva influência nas variáveis macroeconômicas do Brasil, incluindo emprego e geração de renda. Entretanto, a partir de 2014 o cenário econômico do País mudou de forma significativa, para o viés negativo, por decorrência do ambiente de negócio internacional e das condições institucionais da Petrobras. $\mathrm{O}$ posicionamento da Estatal quanto aos seus investimentos futuros, com anúncio de consideráveis cortes no período 2015-2020, a incerteza sobre o Setor de E\&P (petróleo e gás natural) e acerca de geração de emprego e renda no Brasil só se acentuaram.

Em vista disto, importante assinalar que no período 2007-2013 o emprego total na Indústria de petróleo e gás natural aumentou $22 \%$ - sendo que no segmento de Exploração e Produção este crescimento foi de 42\%. Mas com a crise no Setor, enquanto em 2012 o Segmento de E\&P absorveu 62 mil empregados celetistas, ou seja, 12\% do total de ocupação nesta Indústria, em agosto de 2015 o total de ocupações na E\&P caiu para 55 mil, ou seja, respondeu por $10 \%$ dos empregos da indústria de petróleo e gás natural. (COLOMER \& RODRIGUES, 2015, p. 49)

Nesta dinâmica, a Região Sudeste do Brasil é a que mais sofreu os impactos negativos desta Crise política e econômica. Só em agosto de 2015 o Sudeste respondeu por 54\% da redução do nível de emprego no Setor Petrolífero. Assim, no período 20082009 o Estado do Rio de Janeiro foi responsável por mais de 80\% das ocupações em Exploração e Produção. Em 2014 respondeu por 64\%. Deste modo, se em 2013 havia 41 mil trabalhadores no Setor de E\&P, em agosto de 2015 o montante foi de 35 mil redução de $15 \%$ no Setor. Vale informar que o desemprego no Setor de petróleo e gás natural, no Brasil, também segue - além de questões internas - tendência global. Em vista disto, por exemplo, os Estados Unidos, na sua Indústria Extrativa, na qual está classificada atividades circunscritas à extração de petróleo e gás natural, perderam 30 mil postos de trabalho em 2015. (COLOMER \& RODRIGUES, 2015, p. 50)

Deste modo, o cenário global de incertezas e volatilidade no Setor Petróleo também retrata questões de expansão de fontes de energias renováveis e de novos players da Indústria de petróleo e gás natural. Este cenário crítico, associado à queda de preços do petróleo no mercado internacional, impacta sobremaneira a Petrobras. Neste contexto, assinala-se que o investimento acumulado da Empresa, em Exploração e Produção, período 2006-2014, é de R 319 bilhões. Há salto de R 15 bilhões, em 2006, para R \$ 56 bilhões - 2014. Em vista disto, o investimento da Petrobras, segmento de Exploração e Produção, somente em 2013, correspondeu a 5.7\% da formação bruta de capital fixo no País. Entretanto, as condições financeiras da Petrobras, endividamento e dificuldade de se capitalizar, levaram à decisão de redução de investimentos até 2019, ou seja, menos US\$ 76 bilhões - queda de 37\% do que fora antes divulgado no Plano de Negócios 2014-2018. Tal quadro traz mais riscos e incertezas quanto à renda do Brasil, ao seu nível de emprego e acerca de quais ações de Política Pública deverão ser elaboradas e postas em práticas para reativar tanto os investimentos quanto o crescimento do nosso Setor de Petróleo. (COLOMER \& RODRIGUES, 2015, p. 52)

\section{Gestão Organizacional, Terceirização e Organização do Trabalho}


A gestão organizacional está diretamente vinculada à gestão estratégica. Neste sentido, Serra et al. (2014, p. 5) esclarecem que estratégia diz respeito à ação ou às ações que os tomadores de decisão assumem para que os objetivos da empresa ou da instituição sejam alcançados. Deste modo, a gestão estratégica concerne à identificação de estratégias que os executivos delimitarão para que se possa atingir tanto um nível superior de desempenho, inclusive em comparação a concorrentes e ao Mercado em si, quanto a vantagem competitiva. Nesse contexto, além de fatores internos, como recursos humanos de alta qualidade e qualificação, capacidade de inovação e cultura organizacional alinhada para o trabalho conjunto e integrado, fatores externos, como políticos e macroeconômicos, também afetam a efetividade da gestão do Negócio.

Deste modo, a Confederação Nacional da Indústria (2014, p. 13-14) esclarece que ao contrário dos anos 40, do século passado, quando a Consolidação das Leis do Trabalho foi criada, o modelo de produção hoje é horizontalizado, e não verticalizado, condição que faz com que inúmeras empresas atuem em parceria. Desde modo, hoje a exigência estratégica é a de integração entre produção e serviços. Neste cenário, tendo como referência o ano de 2014, a Pesquisa Sondagem Industrial Especial CNI revelou que quase $70 \%$ de 2.330 empresas, de todos os portes, nos últimos três anos, havia utilizado ou utilizam serviços contratado de terceiros. Nesta dinâmica, 62.1\% indicaram a pretensão de manter o patamar de terceirizados, sendo que $21.9 \%$ assinalaram a intensão de aumentar este recurso. O que assume maior relevância é o fato da Terceirização ir além de atividades e apoio. Em vista disto, deste mesmo contingente de empresas, se $34.6 \%$ dos terceirizados atuam em limpeza e conservação e se $51.3 \%$ em vigilância e segurança, outros serviços terceirizados agenciam atividades inseridas na estratégia produtiva, ou seja: $56.3 \%$ em montagem e manutenção de equipamentos industriais; $51.1 \%$ em logística e transportes; $47.3 \%$ em consultorias técnicas; $14.6 \%$ em etapas da cadeia de suprimentos; $12.9 \%$ em pesquisa e desenvolvimento.

Em vista disto, no que concerne a novas formas de organização do trabalho, com foco maior na Inovação, Marx (2011, p. 1-2) assinala que a organização autônoma e flexível diz respeito, inclusive, à organização e gestão por processos e à coordenação das atividades de trabalho direto realizada, de forma prioritária, pelo nível operacional. Completam os requisitos novos o trabalho em grupo com autonomia ou a existência de grupos semiautônomos e a polivalência para que haja competências amplas que lidem com eventos. De igual modo, há a exigência de um novo posicionamento quanto à questão da comunicação e uma política de recursos humanos assentada no Princípio da Competência. Por fim, temos a gestão econômica compatível com demais aspectos organizacionais, além de sistemas tecnológicos avançados. Neste contexto, significativo é o esclarecimento acerca de grupo semiautônomo e grupo enriquecido. O primeiro, semiautônomo, possui maior potencial de inovação, enquanto o segundo, o enriquecido, de mais fácil implantação, mais favorece resultados pertinentes à redução de custos.

Nesta sequência, fica claro então a relevância da interface e da integração entre gestão organizacional, terceirização e organização do trabalho, em especial quanto a inovações organizacionais no cenário do Setor de Óleo \& Gás - com maior ênfase na Exploração e Produção Offshore.

\section{A Petrobrás, a Terceirização e a Divisão do Trabalho}


A Petrobrás (2015, p. 134), Relatório de Gestão 2014, informa:

\begin{tabular}{|c|c|c|c|}
\hline Empregados & $\mathbf{2 0 1 2}$ & $\mathbf{2 0 1 3}$ & $\mathbf{2 0 1 4}$ \\
\hline Petrobras Controladora & 61.878 & 62.692 & 58.618 \\
\hline Controlada e Coligadas - Brasil & 15.547 & 15.903 & 15.293 \\
\hline Exterior & 7.640 & 7.516 & 6.997 \\
\hline Total Sistema Petrobras & $\mathbf{8 5 . 0 6 5}$ & $\mathbf{8 6 . 1 1 1}$ & $\mathbf{8 0 . 9 0 8}$ \\
\hline
\end{tabular}

Tabela 7 - elaborada pelo Autor / Número de Empregados / Fonte: Petrobras (2015, p. 134)

\begin{tabular}{|c|c|c|c|}
\hline Cedidos e Requisitados & $\mathbf{2 0 1 2}$ & $\mathbf{2 0 1 3}$ & $\mathbf{2 0 1 4}$ \\
\hline Cedidos & 49 & 71 & 55 \\
\hline Requisitados & 11 & 11 & 1 \\
\hline
\end{tabular}

Tabela 8 - elaborada pelo Autor / Cedidos e Requisitados para fora do Grupo Petrobras / Fonte: Petrobras (2015, p. 134))

\begin{tabular}{|c|c|c|c|}
\hline Admissões & $\mathbf{2 0 1 2}$ & $\mathbf{2 0 1 3}$ & $\mathbf{2 0 1 4}$ \\
\hline Petrobras Controladora & 2.798 & 1.674 & 360 \\
\hline Controlada e Coligadas - Brasil & 1.219 & 492 & 1.126 \\
\hline Total & $\mathbf{4 . 0 1 7}$ & $\mathbf{2 . 1 6 6}$ & $\mathbf{1 . 4 8 6}$ \\
\hline
\end{tabular}

Tabela 9 - elaborada pelo Autor / Admissões via Concurso / Fonte: Petrobras (2015, p. 134)

\begin{tabular}{|c|c|c|c|}
\hline Terceirizados & $\mathbf{2 0 1 2}$ & $\mathbf{2 0 1 3}$ & $\mathbf{2 0 1 4}$ \\
\hline Petrobras Controladora & 322.720 & 320.152 & 263.766 \\
\hline Empresas Controladas & 28.803 & 30.546 & 18.860 \\
\hline Empresas Controladas (Exterior) & 8.849 & 9.482 & 8.448 \\
\hline Total & $\mathbf{3 6 0 . 3 7 2}$ & $\mathbf{3 6 0 . 1 8 0}$ & $\mathbf{2 9 1 . 0 7 4}$ \\
\hline
\end{tabular}

Tabela 10 - elaborada pelo Autor / Número de Empregados Terceirizados / Fonte: Petrobras (2015, p. 134)

No que diz respeito à Divisão do Trabalho, a Petrobras (2016) aprovou nova estrutura e modelo de Governança. No contexto de redesenho da estrutura e de ampliação de mecanismos de controle e conformidade - interface com novas técnicas de gestão -, a Aprovação sintetiza novos métodos de organização do trabalho ao redistribuir atividades, agenciar fusão de áreas e rever o modelo decisório. Seis Comitês Técnicos Estatutários, com gerentes executivos, analisarão e emitirão Recomendações acerca de temas deliberados por diretores - corresponsáveis no processo decisório. Os Atos dos Comitês estarão sujeitos à fiscalização da Comissão de Valores Mobiliários (CVM). A designação de gerentes executivos obedecerá a novos critérios de análise de integridade e de capacitação técnica e de gestão. O Conselho de Administração aprovará nomeações e desligamentos. Ocorrerá fusão de áreas para aproveitar sinergias. Abastecimento e Gás \& Energia comporão a Diretoria de Refino e Gás Natural.

\section{Conclusão}


No cenário do Offshore, quanto ao desafio da Exploração e Produção de petróleo e gás natural possuir elevado grau de divisão do trabalho e de terceirização, em especial na atual condição de grande redução do preço do barril de petróleo no mercado internacional, significativo é investigar e conhecer quais impactos positivos e/ou negativos a Terceirização apresenta ao Setor. Sabe-se, por exemplo, que no ano de 2014 a Petrobras possuía 263.766 trabalhadores terceirizados da Petrobras Controladora. De Empresas Controladas eram 18.860 e de Empresas Controladas no/do Exterior 8.448. Assim, se havia 291.074 terceirizados no total, havia 80.908 empregados do Sistema Petrobras, bem como 55 cedidos e 1 requisitado para fora do Grupo Petrobras, além de 1.486 admitidos por concurso público. Nesta questão, também é relevante saber em quais segmentos, áreas, unidades e setores estes funcionários estão sediados e com quais percentuais. Isto é fundamental, inclusive, quanto às dinâmicas e processos vinculados à fabricação de coque, de produtos derivados do petróleo e de combustíveis; à fabricação de coque e biocombustíveis (álcool e outros); ao refino do petróleo.

Neste contexto, a elaboração de projetos e a implementação de inovações quanto à organização do trabalho (em especial a divisão do trabalho) e às relações externas (em especial as terceirizações) podem ser impactas pelo fator Terceirização - de diversos modos, qualidades e efetividades. Não obstante, algo que não pode ser esquecido diz respeito à questão grupo semiautônomo e grupo enriquecido. Deste modo, há o fundamental questionamento acerca de como os funcionários terceirizados, do Sistema Petrobras, situam-se e são integrados nesta estrutura: com condições estratégicas e objetivas de assumirem, com efetividade, o papel de inovadores ou, por outro lado, se estão circunscritos à dinâmica de redução de custos. Esta reflexão necessita saber, de igual modo, como este painel é agenciado nos diversos segmentos, áreas, unidades e setores da Petrobras, além de conhecer o perfil sociotécnico deste contingente.

Assim, reforça-se a relevância de Política de Recursos Humanos centrada no Princípio da Competência e instrumentalizada pela prática da Gestão por Competências - Técnicas e Comportamentais. A questão do empresário ou da empresa inovadora é endossada, em particular quanto ao exercício de novas formas de se organizar a produção. Há a indagação acerca de como questões de destruição criativa e de cultura inovadora são demandadas dos trabalhadores terceirizados da Petrobras. Importante é pesquisar, neste recorte técnico das PINTEC 2008 e 2011, de que forma as dimensões de busca, de seleção, de implementação e de captura do valor da Inovação são agenciadas e integradas por terceirizados. Dinâmica de aperfeiçoamento e aprendizagem contínuos são fundamentais. Há também o tópico de capacidades profissionais dos terceirizados para a Inovação dentro do escopo mais amplo de capacitações da Estatal.

Na questão Inovação Organizacional e Terceirizações, no cenário Petrobras, importante também ressaltar o Mundo do Trabalho Contemporâneo no qual há grande ênfase no modelo de produção horizontalizado - mediante o qual empresas atuam, como estratégia de sobrevivência e ampliação de mercado, em parceria. Em vista disto, corrobora-se saber como os profissionais terceirizados da Petrobras atuam, caso atuem, em atividades pertencentes à estratégia produtiva da Empresa - inclusive em consultorias técnicas e em Pesquisa e Desenvolvimento. Deste modo, inclui neste aspecto a qualidade de interface ou de parceria estratégia da Petrobras com demais firmas que agenciam a Terceirização.

No que diz respeito a novos métodos de divisão do trabalho, no escopo da Organização do Trabalho, a Petrobras instituiu nova estrutura organizacional e, assim, o 
seu novo Modelo de Governança. Neste sentido, há inovações quanto à redistribuição de atividades, à fusão de áreas e ao próprio modelo decisório. Deste modo, importante é a reflexão, baseado em Tigre (2014, p. 200), de que mudanças organizacionais são complementos indispensáveis das inovações tecnológicas voltadas a processos tecnológicos. Assim, se a tecnologia necessita ser customizada para um particular cenário microinstitucional, as empresas também precisam alterar as suas rotinas e processos organizacionais para que sejam incorporados, de forma efetiva, as oportunidades disponibilizadas pela inovação organizacional. Deste modo, há o alerta de que mudanças organizacionais costumam ser mais complexas de implementar e impactam processos de negócios e cadeias hierárquicas de comando e controle, além de incidir sobre formas de acesso a informações e nas rotinas e práticas de poder.

Neste contexto, como destacado pela Petrobras (2016) no Informativo Relacionamento com Investidores, a Governança se torna mais relevante e complexa quando se sabe que a Empresa segue regras da Comissão de Valores Mobiliário e da BM\&FBovespa. De igual modo, também cumpre Normas da Securities and Exchange Commision (SEC) e do New York Stock Exchange (Nyse) - Estados Unidos. Também do Latibex da Bolsa y Mercados Espanõles (Espanha), bem como da Comisión Nacional de Valores (CNV) e da Bolsa de Comércio de Buenos Aires - Argentina. Deste modo, a inserção internacional da Petrobras em esferas regulatórias e de controle, no cenário de sua longa crise institucional quanto à Transparência e Prestação de Contas (accountability), em especial a partir de 2014, incentiva a inovação organização acerca da organização interna do trabalho - particular atenção quanto ao Modelo Decisório.

Em vista disto, mediante toda a Reflexão agenciada no Artigo e levando-se em conta a atual Crise do Petróleo, incluindo o impacto dos Mercados de gás natural e de biocombustíveis na Economia nacional e mundial, afirma-se que inovações organizacionais relativas à organização do trabalho e a mudanças nas relações com outras empresas e stakeholders são de fundamental estratégia para a Indústria do petróleo, gás natural e biocombustíveis no Brasil. Deste modo este Setor poderá enfrentar, com melhor efetividade, os desafios de competitividade global - no escopo de considerável queda de preços do barril do petróleo. Isto, no cenário de alta volatilidade e de intensa complexidade e custo de projetos e operações da cadeia produtiva.

Deste modo, significativo é aprofundar a pesquisa, o conhecimento e a análise e avaliação da Inovação Organizacional implementada na Exploração e Produção Offshore - em particular no cenário de intrafirma, mas sem negligenciar variáveis pertencentes a sistemas de inovação e a inovações setoriais. Com isto, como potencial desdobramento desta Reflexão, competências organizacionais e profissionais, uma vez identificadas, mapeadas e interpretadas, têm a força de nortear (micro) políticas de inovação, bem como de treinamento, desenvolvimento e educação da/na Indústria.

Por fim, a conexão do que foi trabalhado ao longo deste Artigo com a Sustentabilidade Econômica e Socioambiental apresenta-se, neste processo, de forma clara e objetiva, em particular quanto ao setor de fabricação de coque, de produtos derivados do petróleo e de biocombustíveis e acerca do setor de coque e biocombustíveis (álcool e outros), incluindo o setor de refino do petróleo - em especial quanto circunscritos à atividade offshore do Pré-sal do Brasil.

\section{Referências Bibliográficas}


ALMEIDA, Edmar Fagundes de. Custos e competitividade da exploração e produção no Brasil. Rio de Janeiro: IBP - Instituto Brasileiro de Petróleo, Gás e Biocombustíveis. Palestra ministrada no Ciclo de Debates sobre Petróleo e Economia - Custos e Competitividade do Setor de Petróleo no Brasil em 20 maio 2016.

ALMEIDA, Edmar Fagundes de. Setor de energia no Brasil: o balanço de 2013. Boletim Infopetro. Rio de Janeiro: Universidade Federal do Rio de Janeiro. Instituto de Economia - novembro/dezembro de 2013 - ano 13 - n. 5 - p. 31-34 ISSN 1679-1355 Disponível em https://infopetro.files.wordpress.com/2014/07/infopetro11122013.pdf Acesso 8 junho 2016.

ALMEIDA, Edmar Fagundes de; LOSEKANN, Luciano. Setor de energia no Brasil: o balanço de 2014. Boletim Infopetro. Rio de Janeiro: Universidade Federal do Rio de Janeiro. Instituto de Economia - novembro/dezembro de 2014 - ano 14 - n. 5 - p. 3337 ISSN 1679-1355 https://infopetro.files.wordpress.com/2014/12/infopetro11122014.pdf Acesso 9 junho 2016.

BRASIL. Ministério do Planejamento, Orçamento e Gestão. Instituto Brasileiro de Geografia e Estatística - IBGE. Diretoria de Pesquisas. Coordenação de Indústria. Pesquisa de Inovação Tecnológica 2008. Rio de Janeiro: IBGE, 2010. 164p. Disponível em

http://www.pintec.ibge.gov.br/index.php?option=com_content\&view=article\&id=45\&It emid=12 Acesso 7 junho 2016.

BRASIL. Ministério do Planejamento, Orçamento e Gestão. Instituto Brasileiro de Geografia e Estatística - IBGE. Diretoria de Pesquisas. Coordenação de Indústria. Pesquisa Inovação 2011. Rio de Janeiro: IBGE, 2013. 227p. Disponível em http://www.pintec.ibge.gov.br/index.php?option=com_content\&view=article\&id=45\&It emid=12 Acesso 7 junho 2016.

COLOMER, Marcelo; RODRIGUES, Niágara. Impactos macroeconômicos da crise na indústria de petróleo no Brasil. Boletim Infopetro. Rio de Janeiro: Universidade Federal do Rio de Janeiro. Instituto de Economia - setembro/outubro de 2015 - ano 15 - n. 4 p. 49-53 ISSN 1679-1355 Disponível em https://infopetro.files.wordpress.com/2015/12/infopetro09102015.pdf Acesso 10 junho 2016.

CONFEDERAÇÃO NACIONAL DA INDÚSTRIA. Terceirização: o imperativo das mudanças. Brasília: CNI, 2014. 71p. Disponível em http://www.portaldaindustria.com.br/relacoesdotrabalho/media/publicacao/chamadas/V 8_Terceirizacaooimperativodasmudancas_web_1.pdf Acesso 14 junho 2016.

MARX, Roberto. Organização do trabalho para a inovação: uma avaliação dos projetos e da implantação de trabalho em grupos com autonomia. São Paulo: Atlas, 2011. 96p.

ORGANIZAÇÃO PARA COOPERAÇÃO E DESENVOLVIMENTO ECONÔMICO. GABINETE ESTATÍSTICO DAS COMUNIDADES EUROPEIAS. Manual de Oslo: diretrizes para coleta e interpretação de dados sobre inovação. 3. ed. OCDE, 1997. Tradução de Financiadora de Estudos e Projetos - FINEP. 184p. Disponível em 
http://www.finep.gov.br/images/apoio-e-financiamento/manualoslo.pdf Acesso 19 junho 2016.

PELLEGRIN, Ivan de; ANTUNES JÚNIOR, José Antonio Valle. Inovação: uma discussão conceitual a partir da perspectiva da cadeia de valor. In: PROENÇA, Adriano; LACERDA, Daniel Pacheco; ANTUNES JÚNIOR, José Antonio Valle; TÁVORA JUNIOR, José Lamartine; SALERNO, Mario Sergio (Org.). Gestão da inovação e competitividade no Brasil: da teoria para a prática. Porto Alegre: Bookman, 2015. 243p.

PETROBRAS. Fatos e dados: aprovamos nossa nova estrutura e modelo de governança. Disponível em http://www.petrobras.com.br/fatos-e-dados/aprovamos-nossa-novaestrutura-e-modelo-de-governanca.htm Acesso 17 junho 2016.

PETROBRAS. Relacionamento com investidores: modelo de governança. Disponível em http://www.investidorpetrobras.com.br/pt/governanca-corporativa/modelo-degovernanca Acesso 21 junho 2016.

PETROBRAS. Relatório de gestão 2014. Brasília: Ministério de Minas e Energia, 2015. 440p. Disponível em http://sites.petrobras.com.br/downloads/aboutus/profile/transparency/doc/AUDITORIA/relatorio-gestao-petrobras-2014.pdf Acesso 16 junho 2016.

PRODANOV, Cleber Cristiano; FREITAS, Ernani Cesar de. Metodologia do trabalho científico: métodos e técnicas da pesquisa e do trabalho acadêmico. 2. ed. Novo Hamburgo (RS): Universidade Feevale, 2013. 277p. Disponível em http://www.feevale.br/Comum/midias/8807f05a-14d0-4d5b-b1ad-1538f3aef538/Ebook\%20Metodologia\%20do\%20Trabalho\%20Cientifico.pdf Acesso em 26 junho 2016.

SERRA, Fernando Ribeiro; FERREIRA, Manuel Portugal; TORRES, Alexandre Pavan; TORRES, Maria Candida. Gestão estratégica: conceitos e casos. São Paulo: Atlas, 2014. 388p.

SICSÚ, Abraham Benzaquen. Desenvolvimento e padrões de financiamento da inovação no Brasil: mudanças necessárias. In: PROENÇA, Adriano; LACERDA, Daniel Pacheco; ANTUNES JÚNIOR, José Antonio Valle; TÁVORA JUNIOR, José Lamartine; SALERNO, Mario Sergio (Org.). Gestão da inovação e competitividade no Brasil: da teoria para a prática. Porto Alegre: Bookman, 2015. 243p.

SCHUMPETER, J. A. Capitalismo, socialismo e democracia. Rio de Janeiro: Zahar, 1984. In: SICSÚ, Abraham Benzaquen. Desenvolvimento e padrões de financiamento da inovação no Brasil: mudanças necessárias. In: PROENÇA, Adriano; LACERDA, Daniel Pacheco; ANTUNES JÚNIOR, José Antonio Valle; TÁVORA JUNIOR, José Lamartine; SALERNO, Mario Sergio (Org.). Gestão da inovação e competitividade no Brasil: da teoria para a prática. Porto Alegre: Bookman, 2015. 243p.

SCHUMPETER, J. A. Capitalismo, socialismo e democracia. São Paulo: Abril, 1982. In: SICSÚ, Abraham Benzaquen. Teoria do desenvolvimento econômico. In: PROENÇA, Adriano; LACERDA, Daniel Pacheco; ANTUNES JÚNIOR, José Antonio Valle; TÁVORA JUNIOR, José Lamartine; SALERNO, Mario Sergio (Org.). Gestão da 
inovação e competitividade no Brasil: da teoria para a prática. Porto Alegre: Bookman, 2015. 243p.

TIDD, Joe; BESSANT, John. Gestão da inovação. 5. ed. Porto Alegre: Bookman, 2015. 633p.

TIGRE, Paulo Bastos. Gestão da inovação: a economia da tecnologia no Brasil. 2. ed. Rio de Janeiro: Elsevier, 2014. 275p. 